\title{
Meditação sobre o ofício de criar $^{1}$
}

Silviano Santiago

Recebido em 22/05/2011

\section{Resumo}

A autoficção é apresentada neste texto híbrido, entre literário e crítico, como lugar de confronto de uma prática de escritor com uma prática de intelectual. O confronto realimenta a reflexão do teórico sobre os paradoxos do eu, a partir da irrupção de uma subjetividade leitora na obra do autor de autoficção.

Palavras-chave: autoficção; subjetividade; escrita

\footnotetext{
1 Este texto foi apresentado numa palestra ministrada no SESC RJ a convite de Luciana Hidalgo.
} 
Em dois livros de ficção publicados recentemente - $O$ falso mentiroso (2004) e Histórias mal contadas (2005) -, tentei dar corpo textual a quatro questões constitutivas do que tem sido para mim o exercício da literatura do $e u$ - as questões da experiência, da memória, da sinceridade e da verdade poética. Se eu aceitei o convite para lhes falar hoje, não foi com a intenção de trazer ao palco o autor dos livros e, com ele, o objetivo de oferecer-lhes uma leitura explicativa daqueles dois e de outros textos autoficcionais meus. Pelo contrário. Só ao leitor compete a tarefa da leitura. Aliás, não sou escritor que busca minimizar o trabalho do leitor; em geral, complico-o. Subscrevo dois versos de Nietzsche/ Zaratustra, que dizem: "odeio todos os preguiçosos que lêem. / Alguém que conhece o leitor, nada fará pelo leitor". Perguntado sobre se encenava peças para seu público, Antonin Artaud respondeu: “O público, é preciso em primeiro lugar que o teatro seja". Em nossas palavras: O leitor, é preciso em primeiro lugar que a literatura seja.

O objetivo primordial desta fala é o de lhes apresentar e, na medida do possível, discutir algumas questões abstratas que preocuparam e preocupam o escritor enquanto personalidade que reflete sobre o estatuto disso a que hoje se chama - e ele próprio passou a chamar - de autoficção. Se pedisse ajuda a João Cabral de Melo Neto, estas palavras trariam como título e intenção "Meditação sobre o ofício de criar". A ele peço de novo ajuda para acrescentar que a meditação "nada tem de pregação e sequer da sugestão de receitas possíveis".

No meu caso, cheguei à autoficção através de um longo processo de diferenciação, preferência e contaminação. Passo primeiro à diferenciação e à preferência. Parti da distinção entre discurso autobiográfico e discurso confessional. Os dados autobiográficos percorrem todos meus escritos e, sem dúvida, alavanca-os, deitando por terra a expressão meramente confessional. Os dados autobiográficos servem de alicerce na hora de idealizar e compor meus escritos e, eventualmente, podem servir ao leitor para explicá-los. Traduz o contato reflexivo da subjetividade criadora com os fatos da realidade que me condicionam e os da existência que me conformam. Do ponto de vista da forma e do conteúdo, o discurso autobiográfico per se - na sua pureza - é tão proteiforme quanto camaleão e tão escorregadio quanto mercúrio, embora carregue um tremendo legado na literatura brasileira e na ocidental.

Já o discurso propriamente confessional está ausente de meus escritos. Nestes não está em jogo a expressão despudorada e profunda de sentimentos e emoções secre- 
tos, pessoais e íntimos, julgados como os únicos verdadeiros por tantos escritores de índole romântica ou neorromântica. Não nos iludamos, a distinção entre os dois discursos tem, portanto, o efeito de marcar minha familiaridade criativa com o autobiográfico e o consequente rebaixamento do confessional ao grau zero da escrita. Em que pese seu legado insuspeito para as culturas nacionais, o discurso autobiográfico jamais transpareceu per se em meus escritos, ou seja, não me apropriei dele em sua pureza subjetiva e intolerância sentimental. Não escrevi minha autobiografia. Uma pergunta se impõe: Então, como tenho valido do discurso autobiográfico nos escritos? Para respondê-la, passemos ao terceiro movimento, o da contaminação.

Ao reconhecer e adotar o discurso autobiográfico como força motora da criação, coube-me levá-lo a se deixar contaminar pelo conhecimento direto - atento, concentrado e imaginativo - do discurso ficcional da tradição ocidental, de Miguel de Cervantes a James Joyce, para ficar com os extremos. Não foi por casualidade que, na juventude, o crítico de cinema se matriculou na Faculdade de Letras e se tornou, na maturidade, professor de literatura. Se minha vida é a que me toca viver, minha formação foi e é estofada pela leitura dos ficcionistas canônicos e dos contemporâneos - independente de nacionalidade. Com a exclusão da matéria que constitui o meramente confessional, o texto híbrido, constituído pela contaminação da autobiografia pela ficção - e da ficção pela autobiografia -, marca a inserção do tosco e requintado material subjetivo meu na tradição literária ocidental e indicia a relativização por esta de seu anárquico potencial criativo.

Inserir alguma coisa (o discurso autobiográfico) noutra diferente (o discurso ficcional) significa relativizar o poder e os limites de ambas, e significa também admitir outras perspectivas de trabalho para o escritor e oferecerlhe outras facetas de percepção do objeto literário, que se tornou diferenciado e híbrido. Não contam mais as respectivas purezas centralizadoras da autobiografia e da ficção; são os processos de hibridização do autobiográfico pelo ficcional, e vice-versa, que contam. Ou melhor, são as margens em constante contaminação que se adiantam como lugar de trabalho do escritor e de resolução dos problemas da escrita criativa.

A força criadora do eu - o que Michel Foucault chama de ressemantização do sujeito pelo sujeito - tropeça na pedra no meio do caminho que é a tradição literária ocidental. Tropeça na pedra, leva tombo, levanta, sacode a poeira, dá a volta por cima e se afirma como também produtora no embate com o poder esmagador da tradição 
ficcional. Dessa forma é que a ressemantização do sujeito pelo sujeito ganha tutano para questionar, pela produção textual, o estatuto contemporâneo tanto da técnica/artesanato da ficção (the craft of fiction, em inglês) quanto do cânone ficcional. Com o correr dos anos, o movimento de vai-vem do questionamento duplo abriu-me uma brecha de intervenção dramática e textual, onde tenho trabalhado as principais características - experiência, memória, sinceridade e verdade poética - da moderna literatura do $\mathrm{eu}$.

A fim de evitar mal entendidos, afirmo que em nenhum momento do passado remoto usei a categoria autoficção para classificar os textos híbridos por mim escritos e publicados. Quando pude, evitei a palavra romance. No caso de Em liberdade (1981), um diário íntimo falso "de" Graciliano Ramos, classifiquei o livro de "uma ficção de", para o desagrado dos editores que preferem o ramerrão do gênero. Já a professora Ana Maria Bulhões de Carvalho o classificou de alterbiografia, um neologismo que já aponta para o caráter híbrido da proposta. Não tive pejo em usar "memórias" para O falso mentiroso. Memórias tem boa tradição ficcional entre nós. ${ }^{2}$

Finalmente, acrescento que fiquei alegremente surpreso quando deparei com a informação de que Serge Doubrovsky, crítico francês radicado nos Estados Unidos, tinha cunhado, em 1977, o neologismo autoficção e que, em 2004, Vincent Colonna, um jovem crítico e historiador da literatura, tenha valido do neologismo para escrever o desde já indispensável Autofiction $\mathcal{E}$ autres mythomanies littéraires (Paris, Tristram). Em suma, passei a usar como minha a categoria posterior e alheia de autoficção.

Meu percurso certamente difere do percurso de Serge Doubrovsky e de Vincent Colonna, e é por isso que aceitei o convite que me foi feito por Luciana Hidalgo para participar deste encontro. Aliás, Colonna é bastante generoso na sua configuração do gênero híbrido - a autoficção, que motivou seu estudo, optando por classificar o conjunto das narrativas afins como "uma nebulosa de práticas aparentadas". Escreve ele que é imensa a lista dos escritores que vêm emoldurando sua identidade numa montagem textual, acrescentando: "Desiguais em sua riqueza, as obras deles são também diferentes pela forma e pela amplidão dos processos de hibridização, mas todas elas marcam uma época, um momento da história literária, em que a ficção do eu [la fiction de soi] ocupa os mais diferentes escritores, para constituir não tanto um gênero, mas talvez uma nebulosa de práticas aparentadas".

Como a autoficção não é forma simples nem gênero adequadamente codificado pela crítica mais recente, eis- 
me à vontade para relatar-lhes meu caminho pessoal. Retorno à distinção inicial entre discurso autobiográfico e confessional.

Não esbocei intencionalmente a distinção e muito menos a arquitetei por artes da inteligência ou da razão. Tampouco a constitui de maneira fria e pragmática como lugar original de minha prática literária. A distinção entre autobiográfico e confessional ganhou corpo textual no momento em que comecei a conjugar minha própria experiência infantil de vida com o auxílio dos verbos de minha memória. Ou seja, desde a mais tenra infância, a distinção entre autobiografia e confissão foi feita e existiu em mim e, desde sempre, existe como força a alavancar a imaginação criadora.

A preferência pelo discurso autobiográfico e a conseqüente contaminação dele pelo discurso ficcional se tornou prática textual, ou seja, elas configuraram um produto híbrido, no momento em que o menino/sujeito teve a imperiosa necessidade de jogar para escanteio - ou para o inconsciente - o confessional e aliar a fala de sua experiência de vida à invenção ficcional. A contaminação se tornou prática propriamente literária no momento em que o adolescente/sujeito - um memorioso estudioso de Letras - revisitava as práticas textuais híbridas da infância para torná-las do domínio público. Ao revisitá-las pelo exercício da memória, tenta apreendê-las com o fim de equacionar o desejo de criar narrativas literárias que signifiquem no universo cultural brasileiro. Muita pretensão? Talvez sim, talvez não. Mas nenhum escritor se realiza sem uma "ambição justa", para retomar a expressão de Autran Dourado.

Portanto, a preferência pelos dados autobiográficos e a contaminação do discurso autobiográfico pelo ficcional existiram desde sempre lá na infância e estarão para sempre em meus escritos. Não tirei distinção, preferência e contaminação do nada, não as inventei recentemente e é por isso que vale a pena pagar uma visita ao menino antigo.

Desde criança, por razões de caráter extremamente pessoal e íntimo - refiro-me à morte prematura de minha mãe - não conseguia articular com vistas ao outro o discurso da subjetividade plena, ou seja, o discurso confessional. Nisso talvez possa me oferecer como paradigmas a infância de Gustave Flaubert e, principalmente, a maturidade de Fernando Pessoa. Não estou querendo dizer que minha personalidade infantil, isto é, meus impulsos vitais e secretos eram-me desconhecidos. Pelo contrário, conheciaos muito bem. Tão bem os conhecia que sabia de seu alto poder de autodestruição e destruição. 
Acreditei ter de esconder dos ouvidos alheios a personalidade de menino-suicida e menino-predador, escondê-la debaixo de discursos inventados (ficcionais, se me permitem), onde eram criadas subjetividades similares à minha, passíveis de serem jogadas com certa inocência e, principalmente, sem culpa no comércio dos homens. Criava falas autobiográficas que não eram confessionais, embora partissem do cristal multifacetado que é o trágico acidente da perda materna. Já eram falas ficcionais e, como tal, co-existiam aos montões. Nenhuma das falas era plena e sinceramente confessional, embora retirassem o poder de fabulação da autobiografia. O dado confessional que poderia chegar à condição plena ficava encoberto, camuflado, para usar a linguagem da Segunda Grande Guerra, então dominante. Não tinha interesse em escarafunchá-lo. Os fatos autobiográficos fabulam, embora nunca queiram aceitar a cobertura da fala confessional, visto que se deixavam apropriar pelo discurso que vim a conhecer no futuro como ficcional. híbrido.

O sujeito ressemantizava o sujeito pelo discurso

Não estou querendo dizer que não vivia a angústia de não poder articular em público o dado da subjetividade plena, dita confessional. Vivia-o, só que não o exercitava como fala nem o escrevia. Agarrar-me e subtrair-me a essa angústia era o modo vital da sobrevivência do corpo e dos impulsos vitais, era o modo como o discurso autobiográfico se distanciava do discurso confessional e já flertava, inconscientemente, com o discurso ficcional. Onde mais forte se fazia o sentido da angústia e mais necessária sua subtração era à mesa de jantar ou no confessionário. Fiquemos com este exemplo.

Meu pai não era católico praticante, mas nos obrigava a ser. Segui o catecismo e fiz primeira comunhão. Ia à missa todos os domingos. Aos sábados, diante do padre-confessor de sotaque germânico (para as conotações, veja-se o período histórico), no escurinho protegido pelas grades do pseudo-anonimato (morava numa cidade do interior), tinha de fazer exame de autoconsciência e ser sincero ao enumerar e confessar os pecados da semana. Costumava trazê-los escritos numa folha de papel. Uma pitada de paranóia, e acrescento que os pecados eram muitos e, perdão pelo trocadilho, inconfessáveis. Apesar da lista avantajada, não proferia no confessionário uma fala sincera, confessional. Mentia. Ficcionalizava o sujeito - a mim mesmo - ao narrar os pecados constantes da lista. Inventava para mim e para o padre-confessor outra(s) infância(s) menos 
pecaminosa(s) e mais ajuizada(s), ou pelo menos onde as atitudes e intenções reprováveis permaneciam camufladas pela fala.

Essas mentiras, ou invenções autobiográficas, ou autoficções, tinham estatuto de vivido, tinham consistência de experiência, isso graças ao fato maior que lhes antecedia - a morte prematura da mãe - e garantia a veracidade ou autenticidade. Aos sábados, diante do confessor, assumia uma fala híbrida - autobiográfica e ficcional - verossímil. Era "confessional" e "sincero" sem, na verdade, o ser plenamente. $\mathrm{O}$ menino ao confessionário já era um falso mentiroso. Faço minhas as palavras contundentes de Michel Foucault em A arqueologia do saber: "Não me pergunte quem sou eu e não me diga para permanecer o mesmo: é uma moral de estado civil; ela rege nossos papéis. Que ela nos deixe livres quando se trata de escrever".

Na infância, já era multiplicadoramente confessional e sincero, era autoficcionalmente confessional e sincero. $\mathrm{O}$ discurso confessional - que nunca existiu no domínio público - se articulava e se articulou desde sempre pela multiplicação explosiva dos discursos autobiográficos que faziam pacto com o ficcional. O discurso confessional - que na verdade não o era, era apenas um lugar vazio, desesperador, preenchido por discursos híbridos - só poderia estar plena e virtualmente num feixe discursivo, numa soma em aberto de discursos autoficcionais, cujo peso e valor final seriam de responsabilidade do padre-confessor - e, hoje, de meu leitor. Ao padre-confessor e ao leitor passava algumas histórias mal contadas.

A boa literatura é uma verdade bem contada... pelo leitor... que delega a si - pelo ato de leitura - a incumbência de decifrar uma história mal contada pelo narrador. Competiu aos ouvidos do padre-confessor - e compete hoje aos olhos do leitor - preencher os brancos e os vazios de que é também feito um texto literário, aliás, não tenhamos dúvida, qualquer texto, que o diga o psicanalista. Compete ao leitor empinar (como a uma pipa) e endireitar (como a algo sinuoso) um objeto em palavras que lhe é dado de maneira corriqueira e aparentemente em desordem. Um exemplo? Pois não. Dom Casmurro é uma história mal contada pelo narrador Bentinho sobre o adultério de sua esposa, Capitu, com Ezequiel, o melhor amigo do casal. Caso narrada da perspectiva do leitor, a estória em primeira pessoa sobre o adultério de Capitu se transforma numa bem contada história sobre o ciúme doentio do personagem Bentinho.

As histórias - todas elas, eu diria num acesso de generalização - são mal contadas porque o narrador, independentemente do seu desejo consciente de se expressar 
dentro dos parâmetros da verdade, acaba por se surpreender a si pelo modo traiçoeiro como conta sua história (ao trair a si, trai a letra da história que deveria estar contando). A verdade não está explícita numa narrativa ficcional, está sempre implícita, recoberta pela capa da mentira, da ficção. No entanto, é a mentira, ou a ficção, que narra poeticamente a verdade ao leitor.

Um dos grandes temas que dramatizo em meus escritos, com o gosto e o prazer da obsessão, é o da verdade poética. Ou seja, o tema da verdade na ficção, da experiência vital humana metamorfoseada pela mentira que é a ficção. Trata-se de óbvio paradoxo, cuja raiz está entre os gregos antigos. Recentemente, encontrei a forma moderna do paradoxo num desenho de Jean Cocteau, da série grega. Está datado de novembro de 1936. No desenho vemos um perfil nitidamente grego, o do poeta e músico Orfeu. De sua boca, como numa história em quadrinho, sai uma bolha onde está escrito: "Je suis un mensonge qui dit toujours la vérité" (Sou uma mentira, que diz sempre a verdade). Esse jogo entre o narrador da ficção que é mentiroso e se diz portador da palavra da verdade poética, esse jogo entre a autobiografia e a invenção ficcional, é que possibilitou que eu pudesse levar até as últimas conseqüências a verdade no discurso híbrido. De um lado, a preocupação nitidamente autobiográfica (relatar minha própria vida, sentimentos, emoções, modo de encarar as coisas e as pessoas, etc.), do outro, adequá-la à tradição canônica da ficção ocidental.

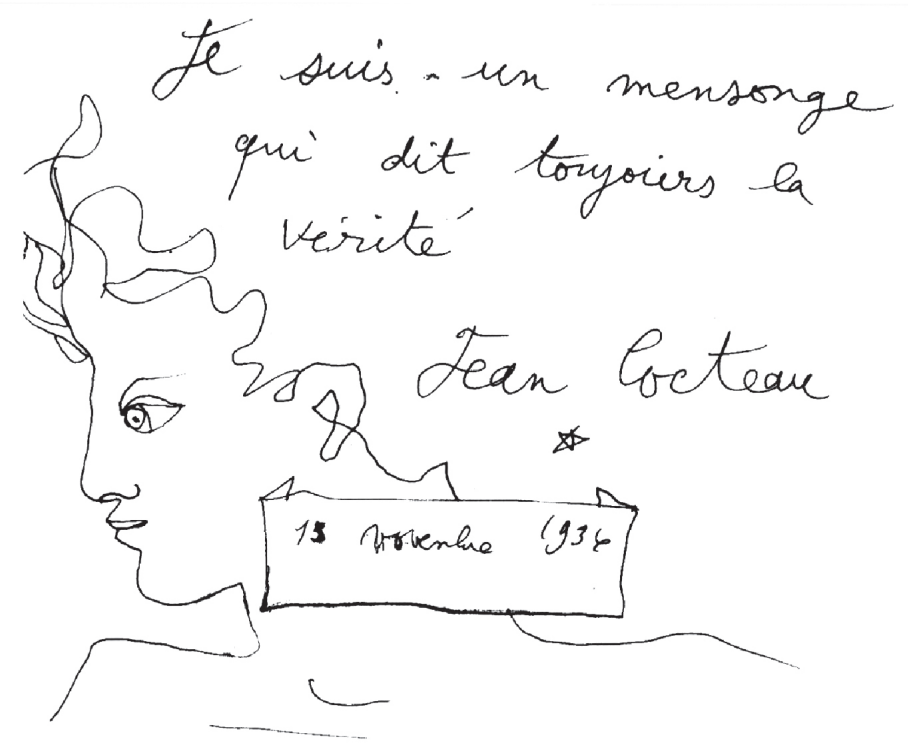

Figura 1: desenho de Jean Cocteau 
Toda narrativa ficcional em que a verdade poética está transparente - aquilo que se chama de romance de tese - é um saco. A verdade ficcional é algo de palpitante, que requer sismógrafos, estetoscópios, e todos os muitos aparelhos científicos ou cirúrgicos que levam o leitor a detectar tudo o que vibra, pulsa e trepida no quadro da aparente tranqüilidade da narrativa literária, ou seja, no mal contado pela linguagem. Nesse sentido, e exclusivamente nesse sentido, o bem contado é a forma superficial de toda grande narrativa ficcional que é, por definição e no seu abismo, mal contada.

Para terminar, leio parte dum fragmento de "Sem aviso", texto assinado por Clarice Lispector: "Comecei a mentir por precaução, e ninguém me avisou do perigo de ser precavida, e depois nunca mais a mentira descolou de mim. E tanto menti que comecei a mentir até a minha própria mentira. E isso - já atordoada eu sentia - era dizer a verdade. Até que decaí tanto que a mentira eu a dizia crua, simples, curta: eu dizia a verdade bruta". Permitam-me a glosa. O sujeito em primeira pessoa começou a mentir por prudência e cautela e, como a realidade ambiente o incitava a ser prudente e cauteloso, continuou a mentir descaradamente. E tanto mentia, que já mentia sobre as mentiras que tinha inventado. E a tal ponto mente, que a mentira se torna o meu modo mais radical de ser escritor, de dizer a verdade que lhe é própria, de dizer a verdade poética.

\begin{abstract}
Self-fiction is presented in this hybrid text, somewhat critical and literary, as the locus of confrontation between an author's practice and his practice as an intellectual. This conflict prompts theoretical reflections on the paradoxes of the self; as an eruption of a reader's subjectivity in the work of the writer of self-fiction.
\end{abstract}

Keywords: self-fiction; subjectivity; text 